\title{
Role of Splenic Artery Embolization in Gastric Variceal Hemorrhage due to Sinistral Portal Hypertension
}

\author{
Bibin Sebastian ${ }^{1}$ Soumil Singhal ${ }^{1}$ Rohit Madhurkar \\ ${ }^{1}$ Department of Interventional Radiology and Interventional \\ Oncology, BGS Gleneagles Global Hospitals, Bangalore, India \\ 2Department of Gastroenterology, Government Medical College, \\ Calicut, India
}

\begin{abstract}
Address for correspondence Bibin Sebastian, MD, DNB, EDIR, Department of Interventional Radiology and Interventional Oncology, BGS Gleneagles Global Hospitals, Bangalore 560060, Karnataka, India (e-mail: drbibinsebastian@gmail.com).
\end{abstract}

\begin{abstract}
Keywords

- sinistral portal hypertension

- splenic artery embolization

- fundal gastric varices

- splenic vein thrombosis

Sinistral or left-sided portal hypertension is a localized form of portal hypertension usually due to isolated obstruction of splenic vein. Most commonly, it is secondary to pancreatitis. Rarely this can present as life-threatening gastric variceal bleeding. In such patients, splenectomy is traditionally considered as the treatment of choice to relieve venous hypertension. Unfortunately, a surgical operation may not be safe in most of the patients because of the unfavorable operative field. Splenic artery embolization (SAE) is an effective method, theoretically akin to splenectomy, blocking the direct arterial inflow to the spleen and thereby reducing the outflow venous pressure. The authors demonstrate a case of a 58-year-old man who presented with severe gastric variceal hemorrhage due to sinistral portal hypertension (SPH) secondary to an episode of pancreatitis, which he had 1 month back. He was successfully managed by SAE and remains symptom-free. The authors bring to the fore the potential curability of gastric variceal hemorrhage secondary to SPH using SAE, which is a safe and effective interventional radiologic procedure.
\end{abstract}

\section{Introduction}

Sinistral portal hypertension (SPH) is a rare entity with an incidence of $<1 \%{ }^{1}$ It is characterized by localized portal hypertension, most commonly due to thrombosis of splenic vein resulting in venous hypertension. This may lead to gastric variceal formation, which eventually may cause life-threatening hematemesis. SPH is also known as left-sided, regional, segmental, isolated, or splenoportal hypertension. Such a condition is traditionally treated by splenectomy aiming at the reduction of gastric variceal pressure building up from the splenic side. Splenic artery embolization (SAE) is a proven endovascular treatment for various disease processes and is emerging as a surgical substitute where it is clinically appropriate. Its role in SPH is not well known and is always placed down among the list of indications for SAE.

We attempt to review the role of SAE as a curative treatment for gastric variceal hemorrhage secondary to SPH along with the demonstration of a case of SPH presented to our hospital with life-threatening gastric variceal bleeding, which was successfully managed by SAE highlighting the shifting trend of management options from surgical to interventional radiology technique.

\section{Splenic Arterial Anatomy}

As endovascular physicians, the fact which we need to keep in mind is that the splenic artery not only supplies the spleen, but also the parts of the pancreas (arteria pancreatica magna and the dorsal pancreatic artery) and stomach (short gastric, posterior gastric, and left gastroepiploic arteries). ${ }^{2}$ These arteries need to be demonstrated by angiogram especially the greater pancreatic artery to avoid unintentional embolization and complications. Hence, embolization should be done distal to the origin of pancreatic branches. At the hilum, splenic artery divides into superior and inferior terminal branches, which further divides into multiple segmental intrasplenic arteries. Majority of the spleen is supplied by the superior terminal branch. received

April 16, 2018

accepted after revision

July 27, 2018

published online

November 27, 2018
DOI https://doi.org/

10.1055/s-0038-1675858

ISSN 2457-0214.
(C2019 by Indian Society of Vascular and Interventional Radiology
License terms

$($ (1) $\Theta \circledast$ 


\section{Pathophysiology of SPH}

Sinistral portal hypertension is a clinical syndrome characterized by segmental portal venous hypertension and its sequelae, usually secondary to splenic vein thrombosis (SVT). ${ }^{3}$ Most of the time, etiology for SVT is pancreatitis because of its closer anatomic relation ( - Fig. $1 \mathrm{~A}) .{ }^{4}$ Since splenic vein runs along the posterior aspect of the pancreas, any pathology of the pancreas can affect the splenic vein. ${ }^{5}$ Sometimes SPH is associated with unexplained splenomegaly, which is often greater than that of due to portal hypertension if the patient has concomitant liver cirrhosis. ${ }^{6}$ The incidence of SPH is increasing probably due to better diagnosis. Most of the patients with SPH remain asymptomatic making the exact estimation of its incidence difficult, but it is generally considered as $<5 \%$ in patients with portal hypertension. ${ }^{7}$ Development of SPH is not related to the severity of pancreatitis. Single episode of acute pancreatitis can also lead to SVT and present later as gastric variceal hemorrhage secondary to SPH. It can remain asymptomatic in SVT secondary to chronic pancreatitis also. ${ }^{8}$

Pathophysiology of SPH is straightforward (-Fig. 1B). Venous hypertension secondary to splenic vein obstruction is the root cause. ${ }^{3}$ Obstruction of splenic vein results in increased pressure in collaterals that divert blood to superior mesenteric and portal venous systems. This includes the short gastric, gastroepiploic, coronary veins, and the veins located in the fundus of the stomach. The characteristic feature is the formation of exclusive fundal gastric varices without the presence of esophageal varix. This is because the redirected splenic venous blood into the gastric fundal veins via short gastric vessels will eventually decompress via the coronary and epiploic veins into portal system, typically into the main portal vein ( - Fig. $2 \mathrm{~A}$ ). Hence, backpressure is not transmitted to esophageal submucosal veins. ${ }^{9}$ Due to various anatomic variations in the drainage of coronary and epiploic veins, SPH can present sometimes with esophageal varices also and need not always result in portal hypertension and any varix formation at all. ${ }^{10}$

\section{Diagnosis}

Most of the patients with SPH remain asymptomatic. Chronic abdominal pain and upper gastrointestinal (GI) bleeding are the most common complaints. ${ }^{9}$ Diagnosis is most commonly incidental to routine evaluation or in an acute setting where the patient presents with upper GI hemorrhage. Diagnosis is mainly clinical by excluding systemic portal hypertension while imaging plays an important role in ruling out other causes. Most of the time it is difficult to differentiate the cause of variceal hemorrhage from general portal hypertension secondary to hepatic cirrhosis. ${ }^{10}$ It is important to differentiate the etiology because the management is different in varices secondary to general portal hypertension and in SPH. The initial diagnostic procedure is upper GI endoscopy, which shows characteristic fundal gastric varices with sparing of rest of the stomach and esophagus. The endoscopic appearance of varices ranges from evident dilated submucosal veins to multiple thin linear nodularities in the fundal gastric mucosa. ${ }^{11}$

Transabdominal ultrasonography (US) helps in detecting SVT and portal vein thrombosis, but is highly dependent on the anatomic location of the thrombus and its extent of involvement. US is more useful as a diagnostic tool to exclude systemic portal hypertension by excluding hepatic cirrhosis. ${ }^{3}$ Endoscopic ultrasonography (EUS) is more useful than US is in evaluating splenic vein. ${ }^{12}$ It is more useful than US in evaluating the pancreatic parenchyma and to detect any mass lesions or any small focus of pancreatitis. ${ }^{13} \mathrm{EUS}$ is reported to be more sensitive than conventional endoscopy in detecting gastric varices. ${ }^{14}$

\section{Splenic vein - thrombosis or mass effect \\ Blood out flow obstruction \\ Venous hypertension in collaterals}

Short gastric, Gastroepiploic and coronary veins

of upper half of stomach

\section{Gastric varices}

A

Fig. 1 Schematic representation of normal anatomy (A) showing inactive, non-dilated SG, gastroepiploic, and coronary venous system with a patent splenic vein. (B) Flowchart showing events in sinistral portal hypertension. CA, celiac artery; CHA, common hepatic artery; CV, coronary vein; GDA, gastroduodenal artery; IMV, inferior mesenteric vein; LGEA, left gastroepiploic artery; LGEV, left gastroepiploic vein; PHA, proper hepatic artery; PV, portal vein; SA, splenic artery; SGA, short gastric artery; SG, short gastric; SGV, short gastric vein; SMV, superior mesenteric vein; SV, splenic vein. 


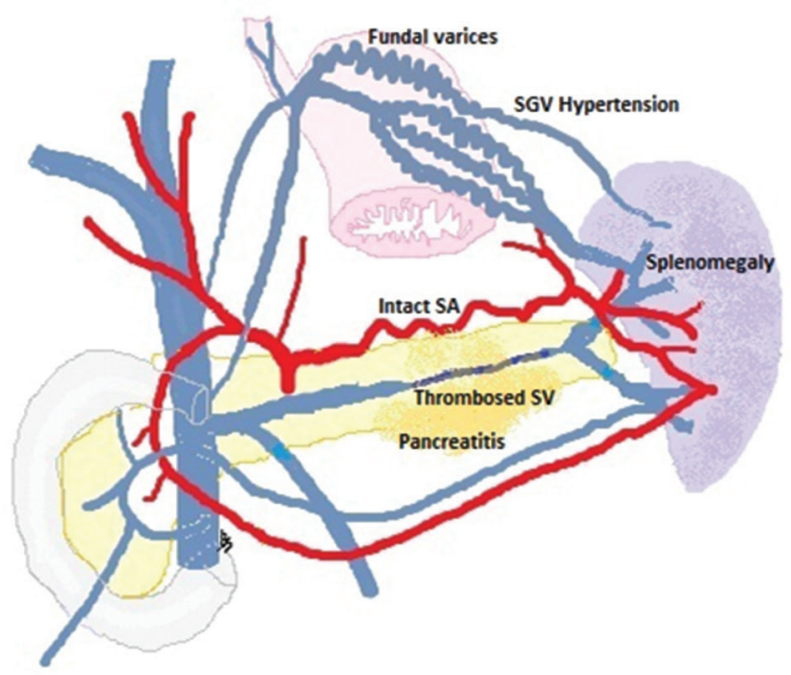

A

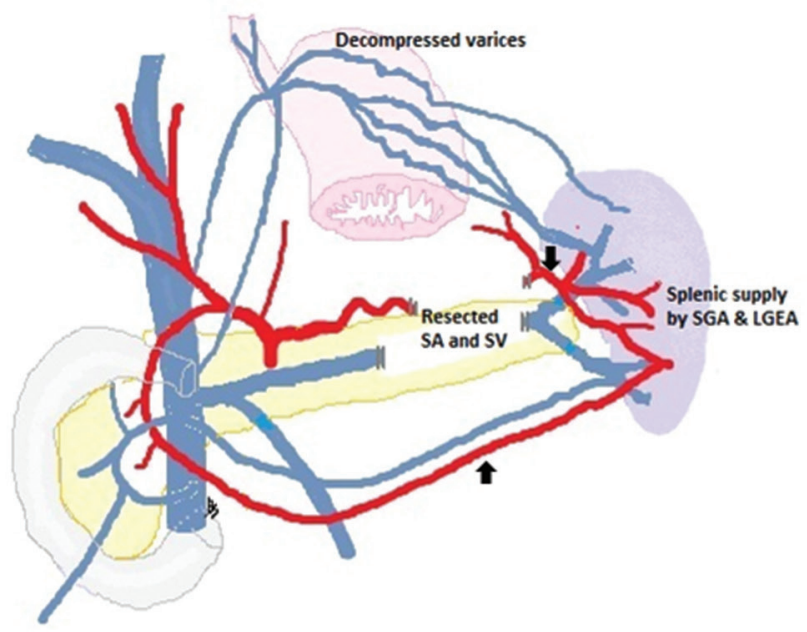

C

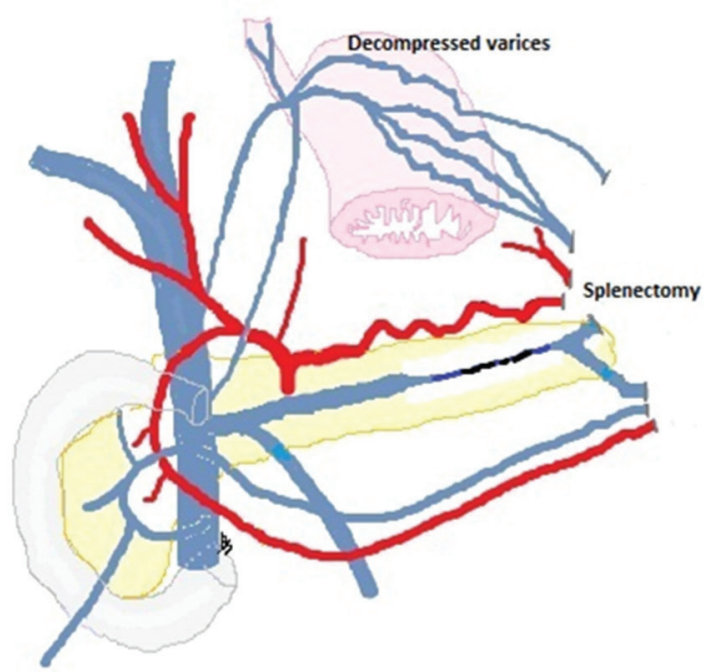

B

Fig. 2 Schematic representation of (A) SPH showing thrombosed splenic vein with patent splenic artery resulting in dilated and tortuous SGV and fundal gastric varices. (B) The principle of splenectomy by blocking the inflow of blood into the SGVs and decompressing it. (C) Warshaw operation, where the spleen is preserved and is survived by arterial and venous systems of SG and LGE vessels. (D) Splenic artery embolization showing a similar mode of action with spleen preserved by SG and LGE vessels. Decompressed fundal gastric varices are also seen in both images (C and D). LGE, left gastroepiploic; LGEA, left gastroepiploic artery; SA, splenic artery; SG, short gastric; SGV, short gastric vein; SPH, sinistral portal hypertension; SV, splenic vein.

Contrast-enhanced computed tomography (CECT) in portographic phase is useful in detecting SVT. It can also demonstrate isolated fundal gastric varices. Pancreatic pathology varying from focal pancreatitis, necrotizing pancreatitis to chronic pancreatitis, can also be seen in this modality. ${ }^{15}$

Digital subtraction angiography (DSA) remains the gold standard diagnostic modality for detecting SVT. ${ }^{16}$ Nonopacification of splenic vein in venous phase of splenic artery injection confirms SVT. It accurately detects the location and extent of thrombosis. Most of the time splenic hilar venous collaterals and opacification of dilated short gastric and gastroepiploic veins are also seen..$^{17}$ All the above-mentioned diagnostic modalities can miss SVT, especially thrombosis of proximal splenic vein which can only be evident intraoperatively. ${ }^{18}$

\section{Management}

Sinistral portal hypertension is one of the curable and rarest syndromes of portal hypertension. ${ }^{19}$ Most commonly patients with SPH present with acute variceal hemorrhage. ${ }^{20}$ 
This may arise from gastric, esophageal, or sometimes even from colonic varices and can be life threatening. ${ }^{21}$ After the initial bleeding control measures to stabilize the patient, treatment is aimed at the reduction in portal hypertension from the splenic side because the rest of the portal system is normal. Medical management including vasoconstrictive agents and endoscopic procedures, such as balloon tamponade and sclerotherapy, are useful only as initial conservative attempts to control bleeding. Most often these methods turn out futile., ${ }^{3,20}$ Unlike in systemic portal hypertension, refractory variceal hemorrhage cannot be controlled by endoscopic banding or proximal portal decompressive procedures, such as portosystemic shunts, which may be even hazardous. ${ }^{22}$

Management of SPH has seen the evolution of its treatment strategy from surgical to endovascular techniques. Earlier, splenectomy was the preferred treatment for SPH. ${ }^{23}$ It was based on the fact that it can cut down the arterial supply to the collateral draining veins and gastric fundal varices and thereby results in the reduction of venous hypertension and risk of bleeding ${ }^{7}$ ( - Fig. 2B). However, splenectomy may not be a safe option for patients who are in an unstable condition due to massive blood loss. Also, the inflammatory process, most commonly like that of pancreatitis, makes the operative field unfavorable. ${ }^{24}$

Splenectomy is also associated with immunological and hematological complications. ${ }^{25}$ This was negotiated by the introduction of 'Warshaw operation,' which is a spleenpreserving operation originally developed for distal pancreatectomy. Segmental resection of splenic vessels result in decreased blood pressure in the spleen and thereby reducing venous hypertension and subsequent resolution of gastric varices. Sufficient blood supply for the survival of spleen and its immunologic functioning will be taken care by short gastric and gastroepiploic vessels ${ }^{26}$ ( - Fig. 2C).

Based on the same principle, SAE can be used as an "endovascular Warshaw operation." Here, embolized splenic artery and the already pathologically thrombosed splenic vein create a similar setting of reduced splenic blood load and resultant variceal decompression similar to Warshaw operation ( - Fig. 2D). SAE in a case of SPH was described as "nonsurgical splenectomy" by Jones and de Koos citing similar reasons. ${ }^{27} \mathrm{~A}$ major concern, as in our case, against performing SAE in SPH is about splenic abscess formation and complete infarction of spleen. ${ }^{22,27}$ This will jeopardize the intention of preserving the immunohematological function of the spleen. Partial SAE can overcome this disadvantage to an extent and can also reduce complications such as post-embolization syndrome. ${ }^{10}$ There is no published data about immunologic consequences after SAE and the role of vaccination prior to non-surgical splenic interventions. ${ }^{28}$ However; some authors are of the opinion that partial SAE is associated with more complications compared with total SAE, especially if the volume of infarction is more than $50 \%{ }^{29}$ As a general rule, complete splenic embolization is not performed due to the possibility of developing severe complications. ${ }^{30}$

Partial SAE can be done in two methods-selective and nonselective. In selective embolization, few distal branches are selectively cannulated and completely embolized, and other vessels are left unembolized. Splenic angiogram in the parenchymal phase subsequently can assess the amount of spleen embolized, and more branches can be selected and embolized if needed. In the non-selective method, the main trunk of the splenic artery is embolized just distal to the origin of pancreatic branches, and the particles are injected until there is a reduction in parenchymal blush. Non-selective embolization is considered superior to selective embolization in SPH. This is because of the reduced amount of splenic infarct and subsequent complications meantime attaining desired preservation of splenic function. . $^{31,32}$

\section{How We Do It}

Our patient was a 58-year-old man who presented with severe hematemesis about 1 month after he had an episode of necrotizing pancreatitis ( - Fig. 3A, B), which was conservatively managed. His hemoglobin $(\mathrm{Hb})$ level was $6.8 \mathrm{~g} / \mathrm{dL}$. He was transfused with two pints of packed red blood cells and was on inotropic support. After stabilizing the patient, a CECT of the abdomen was done, which showed walled-off pancreatic necrosis with SVT ( - Fig. 3C) and prominent gastric varices ( - Fig. 3D). There was splenomegaly. No cirrhotic features were noted. Gastroscopy showed multiple thin varices predominantly in the fundus ( - Fig. $4 \mathrm{~A}$ ), which was not amenable for any endoscopic obliterative procedures. Meantime patient became clinically better with $\mathrm{Hb}$ level of $8.1 \mathrm{~g} / \mathrm{dL}$. Splenectomy was the initial consideration. However, the surgical team refused to intervene citing unfavorable operative field due to severe inflammation and adhesions secondary to pancreatitis.

Splenic artery embolization was offered on interventional radiology (IR) consultation. The decision for SAE was taken after a multidisciplinary team discussion. Main concern during the discussion especially by the surgical team was about the formation of a splenic abscess. This was reassured by the IR team giving the option of pigtail drainage if needed, in case of an abscess formation. Meanwhile the patient had one more episode massive hematemesis (approximately $500 \mathrm{~mL}$ ), and $\mathrm{Hb}$ dropped to $6.6 \mathrm{~g} / \mathrm{dL}$. He was taken up for emergency SAE.

\section{Technique}

Splenic artery access was made via the right femoral artery route using standard angiographic techniques. A $5 \mathrm{~F}$ cobra catheter (Cook Medical) was used for selective cannulation of the celiac artery. Celiac angiogram ( - Fig. $5 \mathrm{~A}$ ) showed normal splenic artery, which was super selectively cannulated using a microcatheter (Progreat, Terumo Corporation) ( - Fig. 5B). Non-selective particle embolization of the splenic artery was done using 300 to $500 \mu \mathrm{m}$ polyvinyl alcohol (PVA) particles (Embosphere Microspheres, Merit Medical System) until there was sufficient stasis of blood flow ( - Fig. 5C). Further coil embolization was done using three micro coils-two $8 \mathrm{~mm} \times 7 \mathrm{~cm}$ and one $2 \mathrm{~mm} \times 7 \mathrm{~cm}$ coils (Nester, Cook Medical). Check angiogram showed absent forward flow ( - Fig. 5D). Pancreatic branches were not visualized, and unintentional embolization of these branches was not of concern in this case since the patient already had 

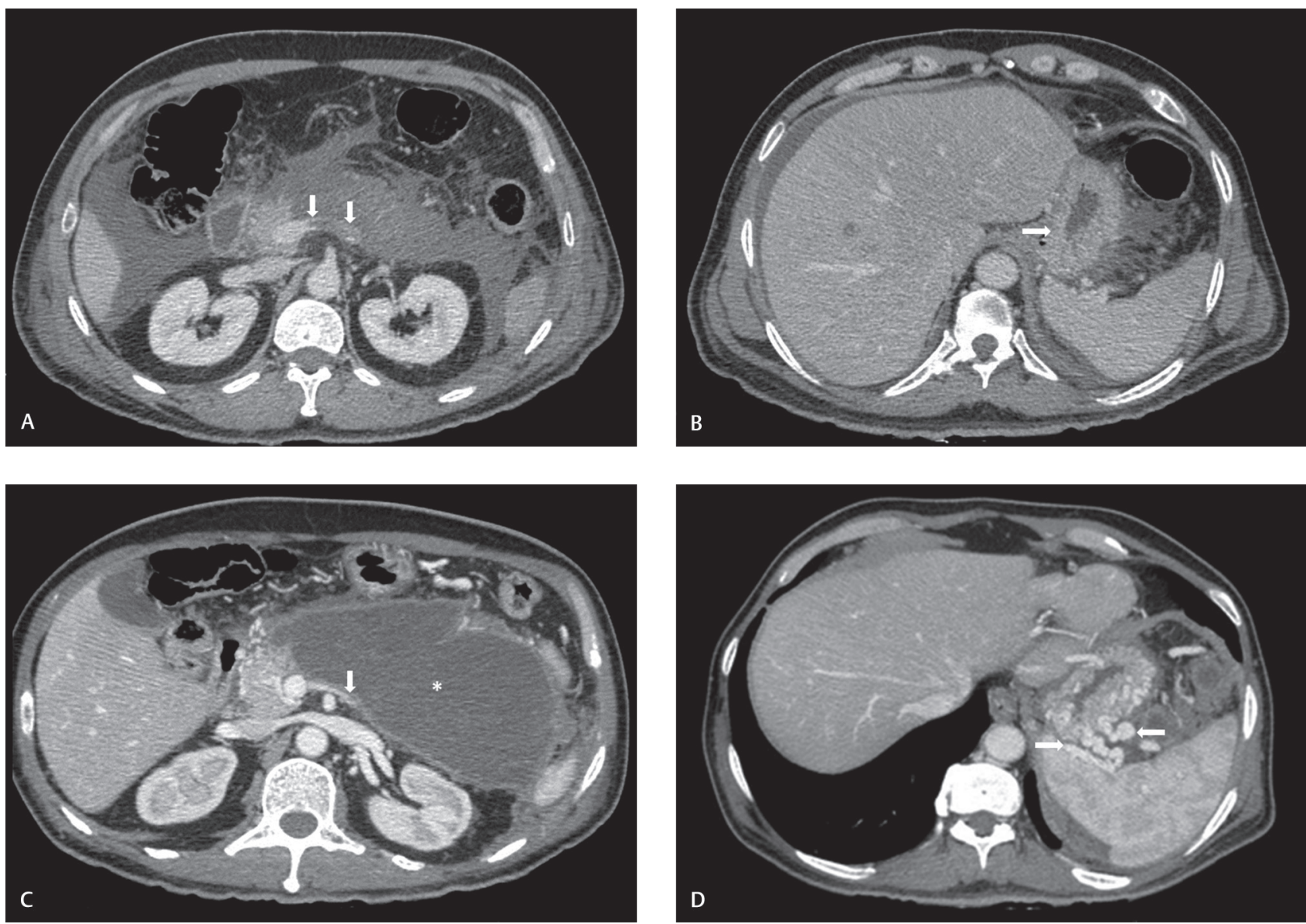

Fig. 3 Axial CECT sections of the abdomen. One month prior to presentation (A and $\mathbf{B}$ ) showing (A) features of acute pancreatitis with acute splenic vein thrombosis (arrows) and (B) no evidence of fundal gastric varices. At the time of presentation, showing (C) walled of necrosis $\left({ }^{*}\right)$ with an occluded splenic vein (arrow). (D) Formation of multiple fundal gastric varices is also seen (arrows). CA, celiac artery; CECT, contrast-enhanced computed tomography; CHA, common hepatic artery; CV, coronary vein; GDA, gastroduodenal artery; IMV, inferior mesenteric vein; LGEA, left gastroepiploic artery; LGEV, left gastroepiploic vein; PHA, proper hepatic artery; PV, portal vein; SA, splenic artery; SV, splenic vein; SGA, short gastric artery, SGV, short gastric vein; SMV, superior mesenteric vein.
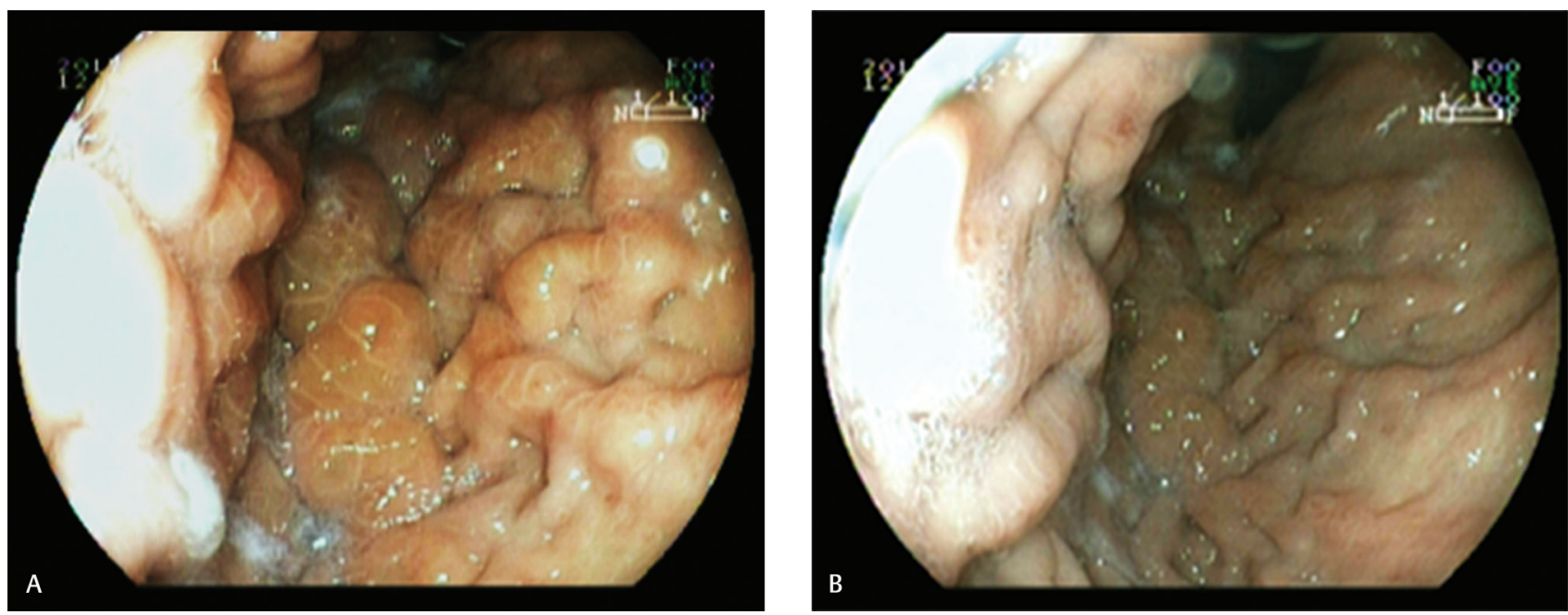

Fig. 4 Gastroscopy showing (A) multiple fundal gastric varices, which shows (B) resolution on immediate post-procedure gastroscopy.

pancreatic necrosis. He was observed in the intensive care unit for a day and was shifted to ward. Gastroscopy on the third day of embolization showed significant reduction in gastric fundal varices ( $\sim$ Fig. 4B). The patient did not develop any post-embolization complications. He was discharged from the hospital on the fourth day of SAE. Follow-up CECT 

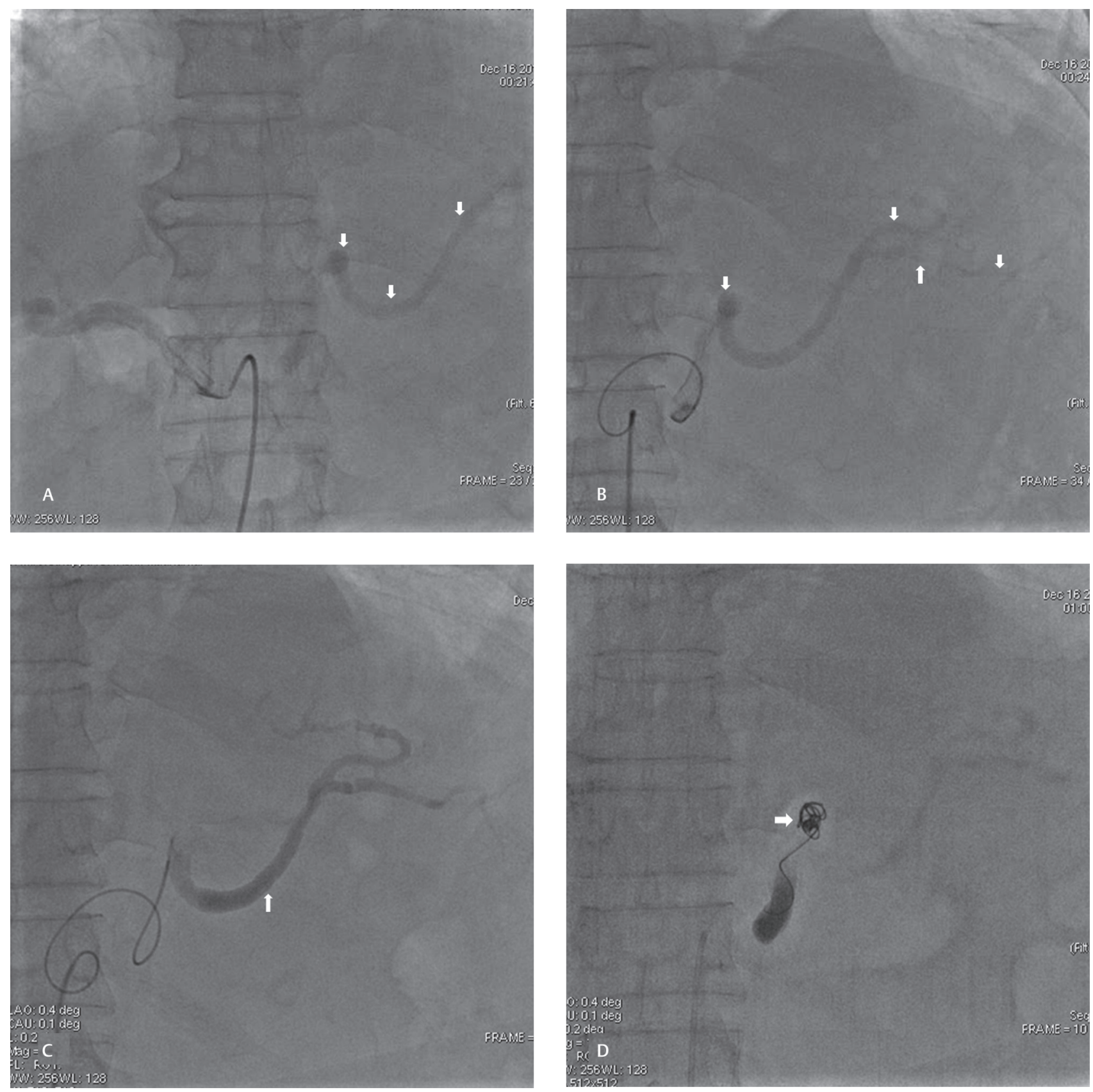

Fig. 5 Angiography. (A) Celiac angiogram showing normal splenic artery (arrows) which was (B) selectively cannulated using a microcatheter. (C) Stasis of flow (arrow) noted in the splenic artery after PVA embolization, and (D) complete occlusion after coil embolization (arrow). PVA, polyvinyl alcohol.

of the abdomen after a month showed complete resolution of gastric fundal varices with near total infarction of the spleen ( - Fig. 6A). Coils in the splenic artery were also demonstrated (-Fig. 6B). There was avascular spleen with altered echotexture with no splenic abscess formation, and the patient was asymptomatic at 4 months follow-up. At 6 months, our patient remained asymptomatic. There was a cystic replacement of entire splenic parenchyma with a small amount of residual tissue in the region of upper pole. Roughly, $85 \%$ infarction of spleen was noted.

\section{Discussion}

The indications for SAE ( - Table 1) involves various specialties. Hence, most of the SAEs are done based on multidisciplinary consensus. There are no absolute contraindications for SAE. Relative contraindications are uncorrectable coagulopathy, severe renal insufficiency, acute or chronic infection of spleen, pregnancy, planned radioiodine therapy for thyroid carcinoma, and contraindications to angiography such as a severe anaphylactoid reaction to iodinated contrast. ${ }^{33}$ 

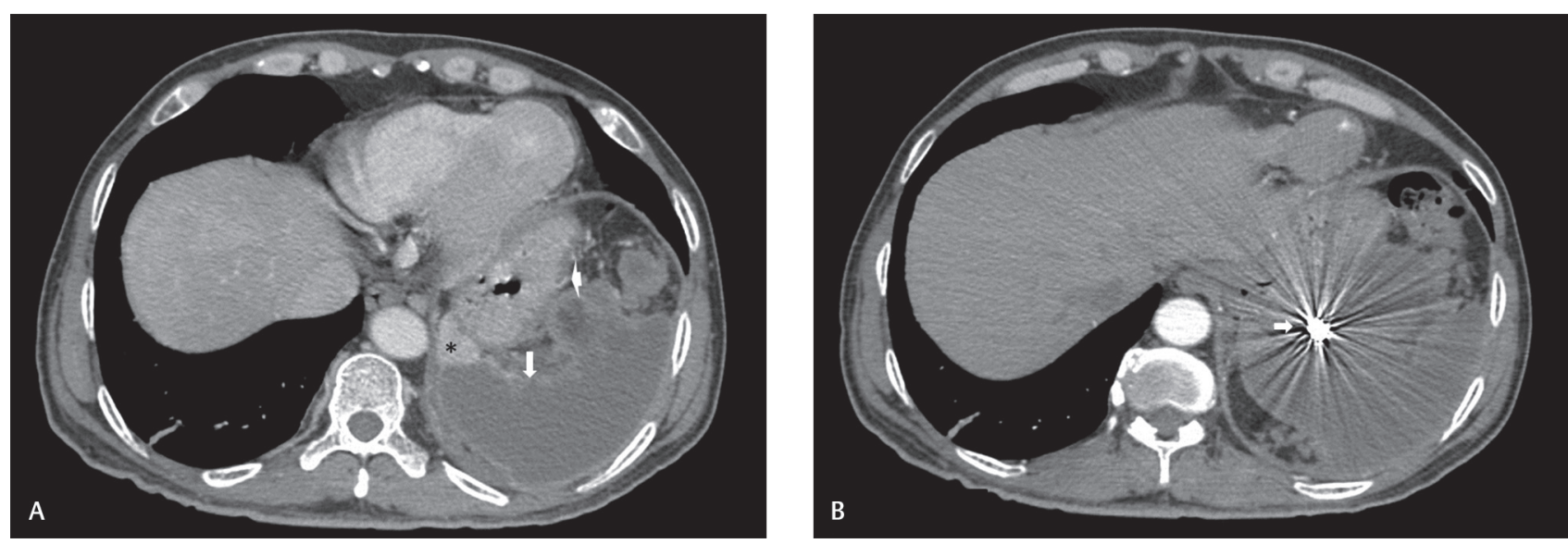

Fig. 6 Axial contrast CECT sections of the abdomen one month after SAE showing (A) near total infarction (long arrow) of spleen with a small preserved area $\left({ }^{*}\right)$. Complete resolution of fundal gastric varices is also seen (short arrow). (B) The coil in the splenic artery (arrow) showing 'streak' artifacts. CECT, contrast-enhanced computed tomography; SAE, splenic artery embolization.

Table 1 Indications for splenic artery embolization

\begin{tabular}{|l|}
\hline $\begin{array}{l}\text { Hypersplenism and hematological disorders-pancytopenia, } \\
\text { idiopathic thrombocytic purpura, thalassemia, hereditary } \\
\text { spherocytosis, and autoimmune hemolytic anemia }\end{array}$ \\
\hline Splenic trauma \\
\hline Splenic artery aneurysm \\
\hline Cirrhosis with portal hypertension \\
\hline Liver transplantation-to treat splenic artery steal syndrome \\
\hline $\begin{array}{l}\text { Hepatocellular carcinoma-to reduce tumor blood supply } \\
\text { and to reduce portal pressure prior to TACE to reduce the } \\
\text { risk of variceal bleeding }\end{array}$ \\
\hline Primary malignancies (leukemia and lymphoma) \\
\hline Idiopathic hypersplenism \\
\hline Sinistral portal hypertension-to treat variceal hemorrhage \\
\hline $\begin{array}{l}\text { Congenital disorders, such as Gaucher's disease and biliary } \\
\text { atresia }\end{array}$ \\
\hline Chemotherapy-associated splenomegaly \\
\hline $\begin{array}{l}\text { Pretreatment for antiviral therapy in hepatitis C virus } \\
\text { infection }\end{array}$
\end{tabular}

Abbreviation: TACE, transarterial chemoembolization.

\section{Embolization Methods}

Partial splenic artery embolization (PSE) is the standard embolization method. This was developed by Spigos et al in $1979 .{ }^{34}$ The most important advantage of PSE, especially over splenectomy is that it maintains the splenic function. This can be done as (i) selective or (ii) non-selective, as described above. In SPH, non-selective SAE appears to be better than selective SAE. Usually, non-selective SAE causes only 20 to $30 \%$ of splenic infarct, which is sufficient to reduce the intrasplenic arterial blood pressure and to achieve resolution of bleeding varices in SPH. ${ }^{31}$

We used coils to block the major vessel proximally to achieve a reduction in overall splenic inflow pressure, ${ }^{35}$ which is the primary intention in any case of SPH. The secondary intention was to reduce the possibility of splenic rupture following embolization, especially because the patient had splenomegaly. ${ }^{36}$ However, coil embolization, which is the preferred method of SAE in trauma, has a disadvantage in this scenario. Spleen gets collateral supply from short gastric and gastroepiploic arteries, which allows itself to repair without infarction. This is beneficial in case of trauma, ${ }^{37}$ but it can result in recurrence of symptoms and failure of treatment in case of SPH. This was tackled by using PVA particles of 300 to $500 \mu \mathrm{m}$, which blocks the splenic blood supply at the parenchymal level so that even if collateralization happens the functional splenic parenchyma undergoes dry infarction. ${ }^{38}$

\section{Embolization Agents}

Most commonly used embolization agents for SAE are coils, PVA, and gelatin pledgets. ${ }^{39}$ Vascular plugs can also be used at the distal splenic artery just proximal to branching of hilar vessels. ${ }^{40}$ Agents like absolute alcohol and lipiodol are cheaper and readily available alternatives. ${ }^{28}$ Silk suture material (4-0 or 5-0) cut in 2-mm length have also been used as embolic agent. ${ }^{38}$ Advantage of smaller particle agents like PVA and 2-mm silk suture bits is that it floats in the blood vessels and reaches downstream and block the vessels supplying the red pulp, which is the functional area of spleen. ${ }^{41}$

Coil embolization is reported to have less post-embolization pain or other complication. However, there is high chance revascularization of spleen and recurrence of symptoms, especially in a case of hypersplenism. ${ }^{41}$ Smaller particles like 300 to $500 \mu \mathrm{m}$ PVA causes early and more severe post-embolization pain. Most likely, this is due to distal embolization and peripheral infarction resulting in exudates and subcapsular fluid accumulation and capsular stretching. However, PVA is effective as a permanent embolization agent because of lesser recurrence rate and decreased incidence of fever and infection compared with other agents.

\section{Complications}

Splenic artery embolization is associated with complications including puncture site-related ones like any other interventional procedures. The incidence of major complications is $\sim 19 \%$ and of minor complications is $\sim 23 \%$. The most common 
major complication is inadequate embolization resulting in persistent hemorrhage. There is only a $3 \%$ chance of developing splenic abscess requiring drainage. Splenic rupture, coil migration, gastric wall necrosis, and pancreatitis are rarer complications. Postembolization syndrome (fever $<39^{\circ} \mathrm{C}$, left upper quadrant pain, nausea, abdominal fullness, and loss of appetite) and reactive left pleural effusion are considered as side effects, not as complications. These symptoms usually last 3 to 10 days. ${ }^{42}$ Postembolization syndrome may be as common as $30 \%$, but usually resolve without any residual effects. ${ }^{43}$

Complications can be minimized by meticulous technique and selective embolization. The severity of complications correlates with the amount of infarcted splenic tissue ${ }^{44}$ Majority of the serious complications occurred when the volume of embolization was more than $80 \%$. Hence, the volume of the first embolization should be less than $70 \%$ to minimize the complications. ${ }^{45}$ In our case, this may be considered as a drawback since we had an infarct of $\sim 85 \%$. However, our patient did not develop any complications. Distal embolization bypassing the splenic and gastric branches can avoid gastric wall necrosis and pancreatitis due to non-target embolization.

Presence of intrasplenic air, unlike in other organs does not always indicate abscess formation. It is reported that only $17 \%$ of cases with intrasplenic air were found to have an infection. This is 50\% if there is a large amount of air. Usually, abscess formation is very rare and can be easily managed percutaneously or rarely by splenectomy. ${ }^{46}$ In general, 'Spigos technique' (-Table 2) has been used to reduce the complications; however, different centers have their own modifications. ${ }^{34}$

\section{Follow-Up}

There is no standard protocol for follow-up in SAE for the treatment of SPH. Continuous monitoring of vitals in an intensive care set up for at least a day post procedure if the patient is hemodynamically unstable. We do serial $\mathrm{Hb}$ monitoring and early post-procedure upper GI endoscopy (usually on the next day of embolization) to assess the hemodynamic status and

Table 2 Spigos technique-general guidelines for splenic artery embolization

Antibiotics: Broad-spectrum systemic antibiotics 8 to 12 hours before procedure and continue up to 1 to 2 weeks. Local antibiotics, such as gentamycin, suspended in embolic solution (not followed nowadays).

Selective catheterization distal to the origin of pancreatic and gastric branches.

Avoidance of excess embolization (not more than $80 \%$ of splenic infarction).

Effective pain control with narcotics or epidural analgesia for 48 hours-to facilitate comfortable breathing and to avoid pulmonary complications, such as atelectasis and pneumonia.

Pre-embolization vaccination against OPSI.

Strict sterility: Wide surgical scrub at catheter insertion site.

Abbreviation: OPSI, overwhelming post-splenectomy infections. the fundal varices, respectively. Immediate resolution of varices compared with pre-procedure endoscopy is usually seen. The patient can be discharged in 3 to 5 days if post-embolization symptoms are relieved. Doppler US examination of the spleen before discharge to look for intrasplenic vascularity and splenic echotexture is usually done. CECT may be done after a month to assess the amount of viable spleen and the fundal gastric varices. Thereafter, serial abdominal US examinations may be done to assess the portal system for any thrombosis and to assess the infarcted spleen if the patient is symptomatic.

In follow-up after SAE for hypersplenism, serial platelet count improvement is noted after a good volume of splenic infarct with a peak response at 3 days and at 1 month. ${ }^{47}$ Platelet count monitoring along with $\mathrm{Hb}$ level may be used as an indirect indicator for successful embolization and for follow-up.

\section{Vaccination}

Routine vaccination in a case of splenectomy is recommended and is effective against overwhelming post-splenectomy infections (OPSI) ${ }^{48}$ OPSI is common after surgical splenectomy as it leads to a state of asplenia. ${ }^{49}$ However, there is no data supporting the routine use of vaccination for OPSI in patients undergoing non-surgical splenic interventions. Its use in non-surgical patients and in partial splenectomy has been reduced..$^{50}$ In a 26 -month follow up study done by Bessoud et al in 24 patients who underwent proximal SAE, only two patients had Howell-Jolly bodies in the peripheral blood indicating inadequate splenic phagocytic function. All the patients had immunity against Haemophilus influenza. ${ }^{51}$ To our knowledge, there is no published data on the immunological outcomes after splenic artery interventions or on the role of vaccination and its routine use in SAE. In our patient, since it was an emergency procedure, vaccination was not given. We feel it is not indicated on follow-up because of the functioning residual splenic tissue in the upper pole.

\section{Conclusion}

Splenic artery embolization is a minimally invasive endovascular procedure, which may be considered as a potentially safe and effective treatment for SPH. SAE avoids splenectomy and can effectively control the gastric fundal variceal bleeding and simultaneously preserve the immunohematological functions of the spleen. We demonstrate an example, which emphasizes the role of interventional radiology in the management and curative treatment of this rare but life-threatening entity. Further evaluation with a large number of cases and long-term follow-up is required to establish the role of SAE in SPH on a larger perspective. However, those physicians who are primarily dealing with SPH should be aware of the role of interventional radiology in the management of SPH and its advantages.

Conflicts of Interest

None.

\section{Acknowledgment}

The authors thank Dr Adarsh CK and Dr Shivaranjan P, Department of Gastroenterology, BGS Global Hospital, Bangalore for their help. 


\section{References}

1 Thompson RJ, Taylor MA, McKie LD, Diamond T. Sinistral portal hypertension. Ulster Med J 2006;75(3):175-177

2 Kadir S, Lundell C, Saeed M. Celiac, superior and inferior mesenteric arteries. Atlas of Normal and Variant Angiographic Anatomy. Philadelphia: Saunders; 1991:204-237

3 Weber SM, Rikkers LF. Splenic vein thrombosis and gastrointestinal bleeding in chronic pancreatitis. World J Surg 2003;27(11):1271-1274

4 Little AG, Moossa AR. Gastrointestinal hemorrhage from left-sided portal hypertension. An unappreciated complication of pancreatitis. Am J Surg 1981;141(1):153-158

5 Moossa AR, Gadd MA. Isolated splenic vein thrombosis. World J Surg 1985;9(3):384-390

6 Blendis LM, Banks DC, Ramboer C, Williams R. Spleen blood flow and splanchnic haemodynamics in blood dyscrasia and other splenomegalies. Clin Sci 1970;38(1):73-84

7 Madsen MS, Petersen TH, Sommer H. Segmental portal hypertension. Ann Surg 1986;204(1):72-77

8 Sakorafas GH, Sarr MG, Farley DR, Farnell MB. The significance of sinistral portal hypertension complicating chronic pancreatitis. Am J Surg 2000;179(2):129-133

9 Köklü S, Yüksel O, Arhan M, et al. Report of 24 left-sided portal hypertension cases: a single-center prospective cohort study. Dig Dis Sci 2005;50(5):976-982

10 Köklü S, Coban S, Yüksel O, Arhan M. Left-sided portal hypertension. Dig Dis Sci 2007;52(5):1141-1149

11 Okuda K, Yasumoto M, Goto A, Kunisaki T. Endoscopic observations of gastric varices. Am J Gastroenterol 1973;60(4):357-365

12 Lewis JD, Faigel DO, Morris JB, Siegelman ES, Kochman ML. Splenic vein thrombosis secondary to focal pancreatitis diagnosed by endoscopic ultrasonography. J Clin Gastroenterol 1998;26(1):54-56

13 Caletti GC, Brocchi E, Ferrari A, Fiorino S, Barbara L. Value of endoscopic ultrasonography in the management of portal hypertension. Endoscopy 1992;24(Suppl 1):342-346

14 Lo GH, Lai KH, Cheng JS, Huang RL, Wang SJ, Chiang HT. Prevalence of paraesophageal varices and gastric varices in patients achieving variceal obliteration by banding ligation and by injection sclerotherapy. Gastrointest Endosc 1999;49(4 Pt 1): 428-436

15 Rahmouni A, Mathieu D, Golli M, et al. Value of CT and sonography in the conservative management of acute splenoportal and superior mesenteric venous thrombosis. Gastrointest Radiol 1992;17(2):135-140

16 Kreft B, Strunk H, Flacke S, et al. Detection of thrombosis in the portal venous system: comparison of contrast-enhanced MR angiography with intraarterial digital subtraction angiography. Radiology 2000;216(1):86-92

17 Illig KA, Spitzer RM, Oates TK. Optimal diagnosis of splenic vein thrombosis: brief clinical report. Am Surg 1997;63(11):1005-1006

18 Köklü S, Köksal A, Yolcu OF, et al. Isolated splenic vein thrombosis: an unusual cause and review of the literature. Can J Gastroenterol 2004;18(3):173-174

19 Babb RR. Editorial: Splenic vein obstruction: a curable cause of variceal bleeding. Am J Dig Dis 1976;21(6):512-513

20 Evans GR, Yellin AE, Weaver FA, Stain SC. Sinistral (left-sided) portal hypertension. Am Surg 1990;56(12):758-763

21 Burbige EJ, Tarder G, Carson S, Eugene J, Frey CF. Colonic varices. A complication of pancreatitis with splenic vein thrombosis. Am J Dig Dis 1978;23(8):752-755

22 Cakmak O, Parildar M, Oran I, Sever A, Memis A. Sinistral portal hypertension; imaging findings and endovascular therapy. Abdom Imaging 2005;30(2):208-213
23 Thavanathan J, Heughan C, Cummings TM. Splenic vein thrombosis as a cause of variceal bleeding. Can J Surg 1992;35(6):649-652

24 Aranda-Narváez JM, González-Sánchez AJ, Montiel-Casado MC, Titos-García A, Santoyo-Santoyo J. Acute necrotizing pancreatitis: surgical indications and technical procedures. World J Clin Cases 2014;2(12):840-845

25 Holdsworth RJ, Irving AD, Cuschieri A. Postsplenectomy sepsis and its mortality rate: actual versus perceived risks. Br J Surg 1991;78(9):1031-1038

26 Ferrone CR, Konstantinidis IT, Sahani DV, Wargo JA, Fernandez-del Castillo C, Warshaw AL. Twenty-three years of the Warshaw operation for distal pancreatectomy with preservation of the spleen. Ann Surg 2011;253(6):1136-1139

27 Jones KB, de Koos PT. Postembolization splenic abscess in a patient with pancreatitis and splenic vein thrombosis. South Med J 1984;77(3):390-393

28 Madoff DC, Denys A, Wallace MJ, et al. Splenic arterial interventions: anatomy, indications, technical considerations, and potential complications. Radiographics 2005;25(Suppl 1): S191-S211

29 He X-H, Gu J-J, Li W-T, et al. Comparison of total splenic artery embolization and partial splenic embolization for hypersplenism. World J Gastroenterol 2012;18(24):3138-3144

30 Madison FE. Embolic therapy of hypersplenism. Invest Radiol 1973;8:280-281

31 Stone PA, Phang D, Richmond B, Gill G, Campbell JE. Splenic artery embolization for the treatment of bleeding gastric varices secondary to splenic vein thrombosis. Ann Vasc Surg 2014;28(3):737.e7-737.e11

32 Sankararaman S, Velayuthan S, Vea R, Herbst J. Severe gastric variceal bleeding successfully treated by emergency splenic artery embolization. Pediatr Int 2013;55(3):e42-e45

33 Kandarpa K, Machan L, Janette D Durham. Splenic and renal embolisation. South Asian edition of Handbook of Interventional Radiologic Procedures. 5th ed. New Delhi, India: Wolters Kluwer; 2017: 283-284

34 Spigos DG, Jonasson O, Mozes M, Capek V. Partial splenic embolization in the treatment of hypersplenism. AJR Am J Roentgenol 1979;132(5):777-782

35 Zhang CQ, Liu FL, Xu HW, et al. [Treatment of esophageal varicose bleeding by percutaneous transhepatic varices obliteration and partial spleen embolization] Zhonghua Gan Zang Bing Za Zhi 2007;15(10):742-745

36 Sclafani SJ, Shaftan GW, Scalea TM, et al. Nonoperative salvage of computed tomography-diagnosed splenic injuries: utilization of angiography for triage and embolization for hemostasis. J Trauma 1995;39(5):818-825, discussion 826-827

37 Link DP, Seibert JA, Gould J, Lantz BM. On-line monitoring of sequential blood flow reduction during splenic embolization. Acta Radiol 1989;30(1):101-103

38 Dehdashti AR, Muster M, Reverdin A, de Tribolet N, Ruefenacht DA. Preoperative silk suture embolization of cerebral and dural arteriovenous malformations. Neurosurg Focus 2001;11(5):e6

39 Hickman MP, Lucas D, Novak Z, et al. Preoperative embolization of the spleen in children with hypersplenism. J Vasc Interv Radiol 1992;3(4):647-652

40 Kim HJ, Park EK, Hur YH, Koh YS, Cho CK. Splenic artery embolization for the treatment of gastric variceal bleeding secondary to splenic vein thrombosis complicated by necrotizing pancreatitis: report of a case. Case Rep Med [Internet];2016. Available from: https://www.ncbi.nlm.nih.gov/pmc/articles/ PMC5116513/. Accessed June 13, 2018

41 Coldwell DM, Stokes KR, Yakes WF. Embolotherapy: agents, clinical applications, and techniques. Radiographics 1994;14(3):623-643, quiz 645-646 
42 Chao CP, Nguyen JH, Paz-Fumagalli R, Dougherty MK, Stockland AH. Splenic embolization in liver transplant recipients: early outcomes. Transplant Proc 2007;39(10):3194-3198

43 Piffaretti G, Tozzi M, Lomazzi C, et al. Splenic artery aneurysms: postembolization syndrome and surgical complications. Am J Surg 2007;193(2):166-170

44 Mozes MF, Spigos DG, Pollak R, et al. Partial splenic embolization, an alternative to splenectomy-results of a prospective, randomized study. Surgery 1984;96(4):694-702

45 N'Kontchou G, Seror O, Bourcier V, et al. Partial splenic embolization in patients with cirrhosis: efficacy, tolerance and long-term outcome in 32 patients. Eur J Gastroenterol Hepatol 2005;17(2):179-184

46 Haan J, Bochicchio G, Kramer M, Scalea T. Air following splenic embolization: infection or incidental finding? Am Surg 2003;69(12):1036-1039, discussion 1039-1040

47 Kimura F, Itoh $\mathrm{H}$, Ambiru S, et al. Long-term results of initial and repeated partial splenic embolization for the treatment of chronic idiopathic thrombocytopenic purpura. AJR Am J Roentgenol 2002;179(5):1323-1326
48 Butler JC, Breiman RF, Campbell JF, Lipman HB, Broome CV, Facklam RR. Pneumococcal polysaccharide vaccine efficacy. An evaluation of current recommendations. JAMA 1993;270(15):1826-1831

49 Bisno AL, Freeman JC. The syndrome of asplenia, pneumococcal sepsis, and disseminated intravascular coagulation. Ann Intern Med 1970;72(3):389-393

50 Wahl WL, Ahrns KS, Chen S, Hemmila MR, Rowe SA, Arbabi S. Blunt splenic injury: operation versus angiographic embolization. Surgery 2004;136(4):891-899

51 Bessoud B, Duchosal MA, Siegrist C-A, et al. Proximal splenic artery embolization for blunt splenic injury: clinical, immunologic, and ultrasound-Doppler follow-up. J Trauma 2007;62(6):1481-1486 